\title{
Leadership coaching experiences of clients with Alexithymia
}

\begin{abstract}
Author:
Frans Cilliers ${ }^{1}$

Affiliation:

${ }^{1}$ Department of Industrial and Organisational Psychology, University of South Africa, South Africa

Correspondence to: Frans Cilliers

Email:

Cillifvn@unisa.ac.za

Postal address:

PO Box 392, Unisa 0003 ,

South Africa

Dates:

Received: 31 May 2011

Accepted: 20 Dec. 2011

Published: 26 Mar. 2012

How to cite this article: Cilliers, F. (2012). Leadership coaching experiences of clients with Alexithymia. SA Journal of Industrial Psychology/SA Tydskrif vir Bedryfsielkunde, 38(2), Art. \#995, 10 pages. http:// dx.doi.org/10.4102/sajip. v38i2.995
\end{abstract}

Orientation: Leaders who find it difficult to connect emotionally with colleagues are often seen as incompetent, the idea that they may suffer from alexithymia - an inability to feel is not taken into account. This coaching model seemed to be not successful in changing this behaviour pattern.

Research purpose: The purpose of the research was to describe the coaching experiences of leaders with symptoms of alexithymia and to formulate hypotheses around their leadership experiences.

Motivation for the study: Effective leadership is strongly associated with emotional connections with colleagues. Leaders suffering from alexithymia, struggle with making these connections. It was thought that coaching might help them bridge the gap towards building effective relationships.

Research design, approach and method: A qualitative research design using case studies was used. Three participants underwent 10 months of systems psychodynamic leadership coaching, including role analysis. Researcher's field notes and participant essays were discourse analysed. The researcher's unconscious experiences were included in the interpretations.

Main findings: Five themes manifested themselves namely, leaders' difficult experiences with coaching, the dynamics underlying their normative, experiential and phenomenal roles and the coach's unconscious experiences affecting the relationship. The research hypothesis referred to the differences between the role parts and the resulting anxiety.

Practical/managerial implications: This coaching model did not provide sufficient opportunities for the participating leaders with regard to emotional reactivity and regulation.

Contribution/value-add: The research created awareness of how alexithymia amongst leaders manifests in organisations. Unfortunately the coaching was unsuccessful in addressing the emotional task. Other ways need to be explored.

\section{Introduction}

Some leaders find it difficult to form emotional connections with colleagues because of the presence of alexithymia, an inability to feel emotionally. Such leaders are often seen as incompetent and 'sent for coaching' to address their cold and aloof style and 'lack of empathy'. An in-depth understanding of the behaviour of these leaders and the nature of alexithymia may assist in realising that coaching about emotionality may not be the answer to this leadership matter.

Leadership is popularly defined as a process whereby an individual influences a group of individuals to achieve a common goal (Northouse, 2004). In all its components of process, influence, interpersonal and group context, and goal attainment, leadership is in its essence an interpersonal activity between leader and follower (Nohria \& Khurana, 2010). The leadership literature classifies leadership competencies as problem-solving skills, social-judgement skills and knowledge (Northouse, 2004). Where both problem solving and knowledge rely heavily on intellectual and cognitive abilities, the social aspect refers to the understanding of behaviour and social systems, understanding of attitudes (thinking, feeling and actions), sensitivity to feelings through empathy and effective communication around emotional, social and work matters. Kets de Vries (2006) included the awareness of and effectiveness in dealing with behavioural dynamics such as conflicts, power relations, resistances and other defensive structures.

The above-mentioned emotional competency is defined (Meyer \& Boninelli, 2007) as the ability to manage emotions within the self, and between the self and the other, amidst diversity in culture, value, ability and behaviour. The leadership literature (see Hughes \& Terrell, 2007) is increasingly linking the above-mentioned competency to emotional intelligence (EQ), which is defined as the ability to perceive, appraise and express emotion accurately and adaptively; the 
ability to understand emotion and emotional knowledge; the ability to access and/or generate feelings when they facilitate cognitive activities and adaptive action; and the ability to regulate emotions in one-self and others (Goleman, Boyatzis \& Mckee, 2008; Snyder \& Lopez, 2002). Although many models of EQ exist, it is generally accepted that it consists of high levels of awareness in own intrapersonal (including control), interpersonal (empathy) and social (realness, respect) behaviour, and skill in social influence (inspiration) and the experience of purpose (authenticity based on deeply felt intentions and values) (Seligman, 2003; Wall, 2007).

Transformational leadership (Van Eeden, Cilliers \& Van Deventer, 2008) as one of the popular theories of the postmodern age (Nohria \& Khurana, 2010), embraces EQ as a desired leadership quality. It is defined as the process whereby the leader engages with the follower in an emotional connection that facilitates the motivation and morality in both parties towards fulfilling the task beyond their self-interest for the good of the group, organisation or society (Bass, 1997; Bass \& Avolio, 1994; Northouse, 2004). The leader's behaviour is characterised by idealised influence, inspirational motivation, intellectual stimulation and individualised consideration (Bycio, Hackett \& Allen, 1995). Thus, leadership includes followership's identification with the leader and the forming of a meaningful trusting relationship (Sievers, 2009). The above was integrated in Avolio's (2007) integrative model of authentic leadership based on how leader and follower regulate the translation of their awareness into behaviours based on authenticity (congruence), transparency and ethics.

Measured against the above competence, it was hypothesised that alexithymic leaders would not cope with the emotional demands of the leadership role. The relevant question here is whether their 'inability to feel' emotionally can be addressed in an organisational context, such as in coaching.

Leadership coaching is generally defined as a regular, short-term and highly focussed organisational learning opportunity (compared to therapy and traditional training). This involves a helping relationship between a client who has managerial authority and responsibility in an organisation, and a consultant who uses behavioural techniques and methods to help the client to improve personal insight towards effective leadership performance and consequently, to improve the effectiveness of the client's organisation, all within the boundaries of a formally defined coaching agreement (Kets de Vries, 2007; Kilburg \& Diedrich, 2007; McKenna \& Davis, 2009). The goal of leadership coaching is to optimise competence in task and people management (Blake \& McCanse, 1995; Lowman, 2002; Sperry, 2004). Most of the coaching studies mentioned in management and organisational psychology (Coutu \& Kaufman, 2009; Harvard Business Essentials, 2004; McGovern, Lindemann, Vergara, Murohy, Barker \& Warrenfeltz, 2001) approach coaching from a mechanistic perspective and report results on cognitive learning about leadership. Coaching in the humanistic paradigm (Stout Rostron, 2009) uses respect and empathy as constructs and reports on the facilitation of self-awareness. Systems psychodynamic coaching includes experiential learning methods (Chapman \& Cilliers, 2008) and reports comparatively deeper levels of insight and awareness in the leadership role and a compelling and dynamic connective quality in the human relationships. According to Kets de Vries and Engellau (2007) this awareness builds an authentizotic organisation.

The purpose of the research was to describe the coaching experiences of leaders with symptoms of alexithymia and to formulate hypotheses around their leadership experiences. The leadership literature is very clear about the desired emotional characteristics of the effective leader and the misuse of emotions to manipulate and harm others (Babiak \& Hare, 2006). Nelson and Hogan (2009) commented on how the dark side of personality can derail occupational performance and leadership competence. On the other hand there is a gap in its reference to the absence of emotional energy, such as in alexithymia and its effect on the leadership-followership interaction.

\section{Alexithymia}

Alexithymia means no word for emotion and is referred to as the deadness within (Kets de Vries, 2001). Its origin and nature are described in three different ways (Berenbaum \& Irvin, 1996; Berenbaum \& Prince, 1994; Kets de Vries, 2001; Lumley, Gustavson, Partridge \& Labouvie-Vief, 2005; Snyder \& Lopez, 2002) namely:

1. neuro-psychological (where poor emotional regulation manifests as a physical, psychological and a communication disorder caused by a genetic neuro-physical defect - a disconnect between the left and right brain hemispheres leading to a deficiency in the transmission of messages from the visceral brain to the language centres of the cortex)

2. a developmental character trait (where the parents are out of touch with their young child's emotional needs and use the child as a drug to solve their own narcissistic conflicts through the child - the child becomes trapped in an aborted symbiotic relationship where extreme dependence is artificially prolonged and the child's true self has not been allowed to emerge)

3. a situation-specific type of coping behaviour (where sociocultural factors follow on particularly stressful events, or a series of events, or extreme situations, such as imprisonment.

The following symptoms of alexithymia are mentioned in the literature (Abe \& Izard, 1999; Apfel \& Sifneos, 1979; Berenbaum \& Irvin, 1996; Berenbaum \& Prince, 1994; Dewaraja, Tanigawa, Araki, Nakata, Kawamura, Ago \& Sasaki, 1997; Friedlander, Lumley, Farchione, \& Doyal 1997; Izard, 1990; Kauhanen, Kaplan, Cohen, Salonen, \& Salonen, 1994; King, 1998; King \& Emmons, 1990; Kooiman, 1998; Lane \& Schwartz, 1987; Lane, Ahern, Schwartz \& Kaszniak, 1997; Lane, Sechrest, Reidel, Weldon, Kaszniak, 
\& Schwartz, 1996; Taylor, Bagby, \& Parker, 1997). On the physical level the individual shows a decreased immune response, a variety of ailments such as hypertension and a decrease in ability to associate physical sensations with emotions. Intellectually the individual reasons in terms of concrete, objective and physical realities, and has a preoccupation with matters external to own experiences and situations, has little understanding of own feelings and of emotional information and may experience judgmental bias. Emotionally the individual is described as numb, blank and cold fish. The individual has an impoverished emotional and fantasy life, is emotionally illiterate, shows an inability to be aware of, identify or differentiate between various emotions, to use metaphors and understand hidden meanings, has a reduced ability to experience emotions consciously, and/or has difficulty in expressing and describing feelings verbally or communicating about them to others. Interpersonally the individual is often in conflict with others and shows an inability to experience or show empathy. Organisationally, alexithymia especially manifests in large systems (such as in government, insurance, banking) with rigid structures and cultures, where emotions are suppressed. Being extremely emotionally cold and detached blends into the culture and becomes seen as normal behaviour.

Based on the above literature review, the following leadership hypothesis was formulated: When leaders exhibit the symptoms of alexithymia of not being able to differentiate between feelings, not to know and share their emotions, not being able to understand or show empathy towards others' feelings and meaning, their colleagues will not be able to make emotional connections with them, which will lead to the breakdown of communication and eventually their relationship.

\section{Systems psychodynamic leadership coaching}

This form of leadership coaching was developed by the Tavistock Institute's (Miller, 1993) Group Relations Training events over the last 60 years (Brunner, Nutkevitch \& Sher, 2006; Fraher, 2004). It consists of a depth psychology organisational theory (Armstrong, 2005; Gould, Stapley \& Stein, 2001) and an organisational development consultancy stance (Neumann, Kellner \& Dawson-Shepherd, 1997). The perspective is based on Freudian systemic psychoanalysis, group relations theory, object relations and open systems theory (Colman \& Bexton, 1975; Colman \& Geller, 1985; Cytrynbaum \& Noumair, 2004) and is theoretically informed by five basic behavioural assumptions, namely, (1) dependency, (2) fight/flight, (3) pairing (Bion, 1961; 2003); (4) me-ness (Turquet, 1974) and (5) one-ness/we-ness (Lawrence, Bain \& Gould, 1996).

The primary task of systems psychodynamic leadership coaching is to provide developmentally and psychoeducationally focussed reflection and learning opportunities to the leader, and to study, become aware of and gain insight into how task and organisational performance are influenced by both conscious and unconscious behaviour (Brunning,
2006; Huffington, Armstrong, Halton, Hoyle, \& Pooley, 2004; Kets de Vries, 2007; Newton, Long \& Sievers, 2006). Consciousness refers to objectivity and rational behaviour, and unconsciousness to the organisation in the mind, which contains the system's unconscious defences and irrational behaviours (Armstrong, 2005).

Systems psychodynamic leadership coaching experientially investigates how specific constructs manifest in the leader's behaviour (Armstrong, 2005; Campbell \& Groenbaek, 2006; Campbell \& Huffington, 2008; Campbell, 2007; Hirschhorn, 1997; Klein, 2005; Vansina \& Vansina-Cobbaert, 2008): anxiety, defined as the fear of the future and acting as the driving force (dynamo) of the relationship and relatedness between leadership and followership; task, the basic component of work, with the leader's adherence to the primary task indicating contained anxiety, and diversions into off-task and anti-task behaviour indicating confusion and anxiety; role, the boundary surrounding work and position, and between leader/follower/ organisation, where leadership is defined as managing the boundaries between what is inside and what is outside the role; authority, the formal and official right to perform the task bestowed from above (the organisation, manager, leader), the side (colleagues), below (subordinates), and from within (self-authorisation); boundaries (such as task, time, territory) which act as the space around and between parts of the system, keeping it safe and contained; and identity, the nature of the leader's role behaviour and the branding, climate and culture of the organisational system.

Coaching starts with role analysis to explore the leader's behavioural dynamics (Newton, Long \& Sievers, 2006). The focus is on the leader in the role within the person-roleorganisation interaction (Huffington, Armstrong, Halton, Hoyle \& Pooley, 2004). Leaders describe their normative (the objective job description and/or content, measured according to performance management), existential (how they believe they are performing) and phenomenal roles (how they believe they perform as experienced by colleagues around them) (Brunning, 2006; Obholzer \& Roberts, 1994). The incongruence between the three parts of the role indicates role anxiety, which is explored to facilitate insight and behavioural change (Newton, et al., 2006). Each subsequent session starts with the open question, 'what is happening with you in your role as leader at the moment'. Coaching sessions do not have specific aims thus ensuring flow of the discourse in the here-and-now (Kets de Vries, 2007).

The coach takes on a reflective stance from a meta position, attending to the leader's behaviour, interpreting the behavioural dynamics in terms of the above basic assumptions and behavioural concepts without judgement, memory or desire (Campbell \& Huffington, 2008). Working hypotheses are formulated, defined as an integrative statement of searching into the leader's behaviour and describing the hereand-now behaviour until new evidence appears (Schafer, 2003). Leaders are encouraged to be curious, to freely associate, to explore a variety of related feelings, patterns, defences and representations (including the transferences 
and counter transferences between leaders and coach), and to move between different levels of abstraction in thought (Jaques, 1990; Kegan, 1994). In this manner leaders can access their own unexplored conscious and unconscious role experiences, attitudes, beliefs, fantasies, wishes, conflicts, social defences, preferences, competition, rivalry, jealousy, envy, hostility, aggression as well as patterns of relationships and collaboration; investigate how parts of the self are split off and projected onto and into other parts of the organisational system (individuals and groups); explore their valences for receiving and containing specific projections on behalf of the system (their projective identification); and consider what can be done to take back the projections and reclaim the lost parts of the self (Blackman, 2004; Campbell \& Groenbaek, 2006; Neumann, et al., 1997; Stapley, 1996; 2006).

The coach's unconscious psychological experiences, specifically transferences and counter transferences, are seen as part of the coaching relationship (Cilliers, Rothmann \& Struwig, 2004). Transference is described as the unconscious shift of memories of past situations and relationships onto the client, then using old defences to forget the past or to master it by living or acting it out again symbolically or by changing the ending thereof (Blackman, 2004). Counter transference is described as the unconscious response to the client's transference (Hunt, 1989). This positioning is useful in understanding how disavowed experiences are placed in objects, including the coach. The role requires using own subjectivity, curiosity, intrigue and suspicion as vehicles of inquiry into the manifestation of behavioural dynamics in the coaching system (Alvesson \& Sköldberg, 2010).

The research problem was formulated as follows: Will leadership coaching offer a good enough containment opportunity for leaders with strong symptoms of alexithymia to significantly increase their emotional awareness and improve the quality of their interpersonal relationships? The first objective was to apply the above coaching model to a group of leaders and to report on their coaching growth experiences. The second objective was to report on the researcher's unconscious experiences as a way of determining the effect of alexithymia on the other in the relationship.

The potential value-add of the research was to make leadership coaches aware of the behavioural dynamics of alexithymia and to hypothesise around the effectiveness of coaching this phenomenon.

The rest of the article is structured as follows. The research design is presented with reference to the research approach and strategy. This is followed by the research method consisting of the setting, roles of the researcher, sampling method, data collection, recording and analysis. Lastly, the strategies employed to ensure quality data are mentioned. Thereafter the findings are presented. In the discussion the research hypothesis is presented, followed by the conclusion, recommendations, limitations and suggestions for further research.

\section{Research design \\ Research approach}

Qualitative and descriptive research was performed (De Vos, Strydom, Fouché \& Delport, 2002) according to the psychosocial approach (Clarke \& Hoggett, 2009). This included phenomenological reduction (Alvesson \& Sköldberg, 2010) in answering the how and why questions of client experiences in a thick, rich and varied description. Hermeneutics was chosen as research paradigm (Terre Blanche, Durrheim \& Painter, 2006).

\section{Research strategy}

A case study design (Chamberlayne, Bornat \& Apitzsch, 2004) was used to empirically investigate the phenomenon of alexithymia in a real-life coaching setting. This allowed for a detailed examination of the manifesting behaviours from multiple sources in a rich description (Creswell, 2003). Three cases were studied individually and then integrated into a collective case study on alexithymia (Hollway \& Jefferson, 2010; Stake, 1995). The cases were seen as intrinsic (providing understanding of the behaviour in the interest of the coaching relationship) as well as instrumental (towards developing knowledge [Denzin \& Lincoln, 2005]).

\section{Research method}

\section{Research setting}

The research comprised three individual leadership coaching clients from different organisations in the manufacturing, financial and educational sectors. Each one underwent 10 months of leadership coaching, comprising of monthly sessions that lasted 90 minutes, and conducted in a meeting room in the clients' organisation. Systems psychodynamic coaching, including role analysis (Newton, Long \& Sievers, 2006), was used.

\section{Entrée and establishing researcher roles}

The researcher took up the roles of consulting psychologist (Lowman, 2002), leadership coach (Brunning, 2006), systems psycho-dynamically informed analysand (Schafer, 2003) and self as instrument (Watts, 2009). He is a psychologist with training and experience in this methodology and fulfilled the requirements for this role as stipulated by Brunner, Nutkevitch and Sher (2006). As researcher, he positioned himself as defended subject (Boydell, 2009), referring to a continuous openness towards his own unconscious and inter-subjective dynamics, such as transference, counter transference and projective identification, and how these affect the research relationship (Alvesson \& Sköldberg, 2010).

\section{Sampling}

Convenient (Brewerton \& Millward, 2004) and opportunistic sampling (Terre Blanche, Durrheim \& Painter, 2006) was used. The three mentioned organisations randomly requested coaching services as part of their standard coaching procedures for the individuals, one Black female (aged 34) and two White males (aged 38 and 43). In their chemistry 
meetings, they framed their coaching issues as 'not getting along with my direct reports', 'I am seen as too cold' and 'people say I have no empathy'. During the first few coaching sessions the researcher realised that all three showed strong symptoms of alexithymia (Kets de Vries, 2001) and decided to use the material as a unique opportunity to study the phenomenon of alexithymia in a coaching context.

\section{Data collection method}

Coaching field notes were made during all coaching sessions, followed up immediately afterwards with detailed comments about the process and dynamics of the session (Hinshelwood \& Skogstad, 2005). After the tenth coaching session, participants were asked to 'write a 4-5 page essay on your learning during coaching' (Camic, Rhodes \& Yardley, 2003).

\section{Recording of data}

The field notes, process and dynamic comments, and essays were integrated per participant and stored in a secure place.

\section{Data analyses}

Two complementary approaches were used, namely, discursive psychology and psycho-dynamically informed discourse analysis (Boydell, 2009). Simple hermeneutics served to interpret the discursive, and double hermeneutics allowed for a critical interpretation (Clarke \& Hoggett, 2009) of systems psychodynamic behaviour (using Armstrong, 2005; Campbell, 2007; Huffington, et al., 2004; Klein, 2005). Triple hermeneutics allowed for interpretations around the researcher as defended subject (Alvesson \& Sköldberg, 2010). This included the researcher's unconscious psychological experiences in terms of transferences, counter transferences and projective identification and the effect thereof on the research relationship. Firstly, single cases were analysed to stay close to their surprising elements, before moving to cross-case analysis and the emergence of themes (Hollway \& Jefferson, 2010).

\section{Strategies employed to ensure quality data}

Ethicality was ensured by obtaining the participants' informed consent, the researcher's concern, care and respect for the participants and their experiences of personal and work-related issues, as well as the responsibility towards scientific data interpretation (Holloway \& Jefferson, 2010). The notion of the defended subject was kept in mind during the coaching sessions and data interpretation (Clarke \& Hoggett, 2009) by suspending memory, desire and judgement (Cytrynbaum \& Noumair, 2004).

Trustworthiness was based on credibility, validity and reliability (Denzin \& Lincoln, 2005). Credibility was ensured through the researcher's competence in systems psychodynamic leadership coaching, his authorisation and role differentiation between coach and researcher, and in the data analysis, between object and subject (De Vos et al., 2002). Validity was ensured by the in-depth (psychological) description of the research, which revealed the complexities of the manifesting themes (Clarke \& Hoggett, 2009). Reliability was ensured by means of careful and scientific planning and presentation of the coaching sessions, and theoretical reliability through scientific data recording, analysis and deep and rich interpretations (Denzin \& Lincoln, 2005). Interpretations were peer reviewed (Brewerton \& Milward, 2004) by an independent psychologist to whom the theoretical model is well-known. He reported positively on the dependability of the findings and the saturation of the data.

\section{Reporting}

The research findings were reported for the collective case per theme and with reference to the experiences of the individual participants where appropriate. In the discussion the coaching behaviour of the leaders was interpreted, their growth during coaching assessed and the identity of the alexithymic leader integrated. The above data were integrated in the research hypothesis. This was followed by the conclusions, recommendations, limitations and suggestions for future research.

\section{Findings}

Five themes manifested themselves, namely, (1) the leaders experiences of coaching, (2) the normative role, (3) the experiential role, (4) the phenomenal role and (5) the coach's experiences.

\section{Leaders experiences of coaching}

The coaching task for all three participants was framed as working towards an increased awareness of feelings and how to use these effectively in interactions with colleagues and followers. Participants seemed detached from the coach as if he was an object in a project. They described him as 'attentive', 'patient', 'sometimes nitpicking', 'going on for so long about so little', and 'krap waar dit nie jeuk nie [scratch where it is not itching]'. One participant remarked, 'halfway through I started to see that he was caring - I think I did not see that at the beginning'. They described the coaching process as 'interesting', 'challenging', 'thought-provoking', 'not quite what I thought it was going to be', 'sometimes too dragged out', and 'helpful towards structuring my work better'. One participant referred to 'those discussion about feelings! I got tired of it. He said I look frustrated, but I don't know how he knows that. Perhaps I was'.

\section{Normative role}

All three participants were intelligent, university and professionally trained and registered with their different professional boards. Two of them served as members of standing committees in their professional societies and one participant received a life membership award from his society. In their organisations, all three were promoted between one and two years ago to director positions in an average of a $50 \%$ professional and $50 \%$ managerial and/or 
leadership ratio. Their roles included their professional work in their individual industries and organisations as well as the management and leadership of their teams of between four and nine direct reports.

\section{Experiential role}

In terms of their background, the participants regarded themselves as having made a good career choice according to their personality, aptitude and temperament. Their choice of employment in their individual organisations was framed as 'a good thing' and 'I thought it would be good for my career'. Cognitively they described their roles and performances by giving lots of information about projects and workflow, which they seemed to be mastering well. Affectively they seemed detached from their colleagues as well as from their role and task. They sometimes used emotional words ('I was happy when that was completed'; 'I thought one was going to be irritated when one was not allowed to ...') - always with reference to the past. Motivationally they referred to the energy they gained from completing projects successfully and how they used the energy to get more involved in the organisation, which included volume as well as complexity. One participant described himself as 'very serious - perhaps too serious', whilst another said, 'I am here to work and get things done'. They reported on driving themselves hard towards attaining their set project goals and financial targets. They implied high levels of loyalty towards their profession and organisations.

Interpersonally the participants referred to their leaders in a cognitive manner as 'a good manager', 'someone that gets things done' and 'makes fire under those who do not contribute'. One participant described his leader as someone who is always trying 'to make feeling conversation - almost like the coach does - that is strange for me'. They described their direct reports and colleagues in a mechanistic and impersonal manner. In session 5 one participant broke out in tears and declared, 'I should never have become a manager - I also do not want to be a leader - whatever that means'. For this participant the realisation and experience of intense frustration was more important than the matters of career choice. Another said in his essay, 'Sartre said hell is other people. I also think so - in my work anyway'.

The participants described themselves in their professional and organisational roles and the standards and performance targets, very positively. This was congruent with their performance management outcomes. Their description of their 'people skills' was different. Participants described this as 'a minefield', 'something that brings me many headaches' - 'I wish I could work without people, especially the difficult ones - you know, the sensitive people'. One participant was promised a promotion on condition that 'if only I could become friendlier. My manager said I lack empathy. Can you [the coach] teach me that?'

\section{Phenomenal role}

The participants' discourses on how others experience them corresponded with their experiential role. They were positively assessed and respected for their career advancement, intellect and motivation. On the other hand, in terms of emotionality, they were described as 'hard/cold/ aloof/like a stone', 'dull' and interpersonally as 'difficult to understand', 'impossible to comprehend'; what makes them 'tick' and 'difficult/impossible to work with'. They were often told that they were inhumane, non-caring, 'treat people as machines' and 'animals', and that they 'have no warmth/compassion/empathy'. The participants used many coaching hours to process 'why others avoid me', 'why my manager only makes contact with me three times a year for my performance reviews', and why 'colleagues exclude me from their after hour's activities'.

\section{The coach's experiences}

After the chemistry sessions with all three participants, I was consciously looking forward to the coaching, impressed by their corporate positions and associated glamour and affluence, their qualifications and intelligence. Unconsciously, I was comparing my (very different) daily work and social reality to the idealised picture of them in my mind. My transference was about people who have everything which made we feel less worthy and envious of what they had. This resulted in feelings of incompetence which created performance anxiety. As this anxiety became unbearable, I started to project my experienced incompetence onto them as a way to hold on to my competence as their coach.

In working through the dependence of the individual on the coach, I realised that the three individual participants had intense difficulty with emotionality and connection (the primary task of their coaching), and that they resisted my inputs and role. My counter transference was a form of counter resistance - which manifested as diminished enthusiasm, impatience and helplessness. I experienced the sessions as drawn out, tedious and tiring, which drained my motivation. I experienced the participants as irritating and projected stupidity onto them. As the coaching progressed, I became aware of my intellectual competition with them by giving clever interpretations of their leadership behaviours and feeling proud of myself. My counter transference was to take them on as if it was an intellectual coaching examination. After a while I realised that I won the competition and that I was stupid (owning my previous projection) to compete with my non-coaching and/or psychologist clients! Unconsciously, I could not step out of the competitiveness, although the content of the fight had changed. In trying very hard to make sense of their non-emotional worlds, I tried to be the best Rogerian psychologist I could. My competitive transference became to reflect through deep empathic listening. The participants stayed emotionally aloof, detached and disinterested. I sensed their irritation but it was always disguised by their rational explanations around how things work for them.

Slowly I started to realise that the participants were performing as best they could (this is as good as it gets) and that my 'emotional labour' (Clarke \& Hoggett, 2009, 
p. 103), unconscious experiences and excessive conscious strategising, was indicative of who is doing the work and in what way the coaching is not effective. My learning was that my response to their behaviour was probably indicative of how their other experienced them daily. Framing their behaviour in terms of projective identification, I realised that they projected their responsibility to have feelings onto me as an authority figure, which then identified with the projection and thus became the container for their emotional experiences and left them dissociated and isolated from their feelings. I searched for and found evidence in their here-andnow coaching discourses for similarities to their leadership responses with colleagues. I felt sad for their inability to experience their feelings, thinking that they probably never had experienced meaningful emotional connections (because of parental relationships) and probably never would. Later I could see that the sadness was also my projection (the sadness did not belong to them).

The exploration of my experiences facilitated my better understanding of their valence to attract, introject and hold the non-feeling parts of their work environment. This made me think of what their work systems and colleagues projected onto and into them, for example the lack of any feeling and emotion. Perhaps they were trusted by their work systems (Bion, 2003) to take on and contain the feeling void (a type of nothingness), which allows the other to be emotional and explorative in terms of feelings.

My feelings of incompetence resurfaced associated with more anxiety. Now I had evidence not only of their leadership incompetence, but also their inability to react to and regulate their feelings. My counter transference was about the pity I felt for them (people who do nott feel can notbe good leaders) and anger towards their organisations (why were they promoted into positions whilst unable to cope with the emotional demands thereof?). My counter transference was to avoid this hopeless situation, which was evident during a period of my dissociation from them, and acting emotionally detached. My avoidance defence also manifested itself when I tried to cancel a scheduled appointment with two of the participants.

Through intense reflection and supervision I regained some realism and objectivity. I could see the issues of the participants separate from mine. I used my rational faculties and studied alexithymia as a behavioural phenomenon. This helped me to realise the extent of the issues of the participants, and I started to emotionally connect with their (assumed) pain and bravery to keep going and tolerate me and the coaching challenges. Working through my field notes I became aware of how often and strongly they told me in different ways that they were not interested in the coaching task, to feel awareness and reactivity, or the process of exploring emotional experiences. My counter transference was to protect them from the organisation that had (in my mind) manipulated them into a coaching situation which was not within their emotional abilities. In my mind, coaching became the organisation's compensation defence against its frustration and desperation to change the employee. I then realised that I colluded in this manipulation by accepting the coaching task. Then I identified with the participants again which lead to my feelings of shame, for being cruel and torturing them. I decided to see the coaching contract through and spent the remaining sessions on supporting their efforts to try and understand their own leadership styles and their efforts to build relationships with colleagues (albeit mostly intellectual).

\section{Discussion}

The purpose of the research was to describe the coaching experiences of leaders with symptoms of alexithymia and to formulate hypotheses around their leadership experiences.

The research was important in its in-depth exploration of the manifestation of alexithymia amongst leaders as well as using the unconscious experiences of the coach in understanding the transferences and projections onto them.

Theme 1 illustrated how leaders experienced coaching as oscillating between being worthwhile and a waste of time. The leaders found it difficult to establish an emotional connection with the coach. Their behaviour was interpreted as a discomfort with psychological intimacy and a desire to maintain psychological independence (Prior \& Glaser, 2006). Although they unconsciously expressed a need for caring and attention from the coach, it was as if they experienced a deep uncertainty about their capacity or willingness to respond to such needs (Rholes \& Simpson, 2004). Their conflict to connect or to not connect was interpreted as an inability to seek and give care, especially under stressful situations. This is described in attachment theory as the inability to form emotional bonds, to self-regulate, express and use emotional resonance, attunement and empathy in their interactions (Colin, 1996; McCluskey, 2005; Prior \& Glaser, 2006; Rholes \& Simpson, 2004). Their behaviour came across as an anxiety of being rejected, abandoned and unloved which could explain their avoidance of intimacy and interdependence. Theoretically the origins of the forming of their poor emotional attachment relates to their experienced non-availability of a secure attachment figure (such as a parent) to offer support under threatening situations. They introjected insecurity developed a non-autonomous identity, felt unworthy of affection and saw attachment figures as non-responsive, non-caring, undependable (McCluskey, 2005; Rholes \& Simpson, 2004). As leaders, they did not have memory of how to form significant emotional attachments. It was hypothesised that the quality of the leaders' relationship with the coach was transferred from previous non-caring and thus disappointing authority figures (Gould, Stapley \& Stein, 2004; Hirschhorn, 1997).

Given the above attachment forming style, the literature (Colin, 1996) predicted low levels of work satisfaction. These leaders showed the contrary - they experienced seemingly above average levels of satisfaction. 
Theme 2 illustrated the leaders' success in their professional roles, their preference for the rational task and avoidance of people management.

Theme 3 illustrated how the leaders experienced themselves positively in taking up their role in terms of career development, cognitive functioning and drive. Initially they could not differentiate between cognitive and emotional demands and reasoned about all their experiences (Diamond \& Allcorn, 2009). Gradually they learned a basic emotional repertoire, but still used it mechanistically and in reference to past experiences. They attached to the rational and cognitive aspects of their roles and detached themselves from the affective parts. Their natural tendency to avoid their people management role and treat the other as objects in their mind (Armstrong, 2005) did not change significantly.

Theme 4 illustrated how the others experienced the leaders as emotionally unavailable and interpersonally detached, which overshadowed their positive career, intellectual and motivational aspects. This finding supported evidence of how dysfunctional leaders cause misery amongst followers (Nelson \& Hogan, 2009).

Theme 5 illustrated the complexity of the unconscious relationship between the leaders and the coach. The coach introjected the emotional labour in the relationship (Clarke \& Hoggett, 2009) - whilst he consciously aimed to maintain the well-being of the relationship, he unconsciously took on an assumed position of knowing and valuing what a proper state of mind might be - suppressing the expression of his own true feeling and acting on behalf of the collective unconscious (Diamond \& Allcorn, 2009). He became the container of the leaders' projections of incompetence around feeling reactivity and regulation. The coach's experience of professional incompetence was derived from his feelings of envy and repulsion towards the leaders. Working through the complex unconscious interpersonal dynamics he could understand how his own dynamics reflected the unconscious world of alexithymia (see Morgan-Jones, 2010).

The leaders' growth was described as limited. They struggled to attach to the coaching task and to take up the role as learner about their own emotional world (Hirschhorn, 1997). Using the unconscious dynamics as evidence, it was interpreted as the leaders not owning their projections towards learning (Czander, 1993). This may have been based on the nature of alexithymia as an inability.

The identity of the leaders with alexithymia was described as follows. They were professionally trained, well established in their careers and performing well in their rational and technical tasks, and physically they often appeared stiff, distant and lacked facial expressions. Cognitively they were highly intelligent and competent in abstract reasoning and differentiation on content and rational matters. Their focus on the concrete was used as a defence against experiencing feelings. Affectively they had a limited feeling repertoire, seemed emotionally empty and apathetic. They could not differentiate between affective nuances (e.g. between glad, sad, mad and bad - see Kets De Vries, 2001) and did not use any metaphors or fantasy language. Their anxiety was about managing to keep their competent cognitive parts inside their role boundaries and their affective and dynamic experiences outside. This defence was a split between thinking and feeling, introjecting and owning thinking (using their high IQ's, cognitive and rational competence, focussing on the concrete and objective) and disowning, denying and dissociating from their feelings ( $E Q$, affective, irrational and subjective abilities) (see Blackman, 2004). This led to a position where their egos were inhibited to grow to its full potential (Kets de Vries, 2001). In organisational terms, the leaders self-authorised through the introjection of their rational task, could not authorise themselves to take up their emotional and people management roles (see Blake \& McCanse, 1995). Motivationally, the leaders seemed tired towards the end of the coaching sessions. It was hypothesised that, although they did not process feelings consciously, the energy they used to cope with the focus on emotional processing indicated how active their emotional energy was, albeit unconsciously. Interpersonally their relationships (including with the coach) were superficial in line with Fromm's (1947) notion of the market orientation. It was also hypothesised that their role anxiety did not originate form the difference between their experiential and phenomenal roles (as is often the case - Obholzer \& Roberts, 1994), but from the splits within both the experiential and phenomenal roles (referring to the co-existence of their competence and incompetence within the same role part).

The research question could not be answered positively - the coaching could not offer the leaders with strong symptoms of alexithymia, a containment opportunity to increase their emotional awareness and quality interpersonal relationships. They could often not understand the rationale for coaching and what the coach was on about. One leader realised that the notion of not being able to show feeling, was much deeper than what could be addressed in leadership coaching. He started therapy to work on the exploration of his family dynamics. The findings corresponded with other coaching research (see Nelson \& Hogan, 2009) illustrating how the dark side of a leader's personality creates a situation where leaders are derailed and incompetent to form relationships with followers. This situation is also reported on in the transformational leadership literature (Avolio, 2007).

The research hypothesis was formulated as follows. The leaders' background and family dynamics kept them stuck in a borderline culture where emotional distance between objects (and thus also people) needed to be maintained in service of the primary task of survival. Their capacity to form an emotional identity was inhibited to such an extent that they were acting as if they were emotionally illiterate. Their well-developed intellectual, rational and professional competencies facilitated their promotions into leadership positions. All three leaders would have been served better by the organisation if they had been kept functioning in professional and specialist roles. From a personal growth 
perspective they were at least exposed to some possibilities towards emotional awareness.

It was concluded that to coach leaders with strong symptoms of alexithymia represents on the one hand feelings of incompetence in the coach, compensated for in emotional labour on behalf of the leader, and on the other hand, minimum growth for the leader. This research showed little evidence of success in coaching alexithymic leaders.

It was recommended that organisations think more rationally about promoting employees into leadership positions. When sent for coaching, leaders who showed symptoms of alexithymia should be informed about the possibilities of low success levels. Alternatively, coaches should explore other coaching models.

A limitation of the research was that the three participants were not neurologically or psychometrically assessed for alexithymia (see Nelson \& Hogan, 2009). This could have assisted the coach in realising the presence and severity of the emotional matters of the leaders sooner.

It was suggested that future research use psychometric instruments to assess the strength of the alexithymia behaviour to ensure clear cases of this phenomenon (see Snyder \& Lopez, 2002, p. 177 for examples of such instruments).

\section{Acknowledgements \\ Competing interests}

The author declares that he has no financial or personal relationship(s) which may have inappropriately influenced him in writing this paper.

\section{References}

Abe, J., \& Izard, C. (1999). A longitudinal study of emotion expression and personality relations in early development. Journal of Personality and Social Psychology, 77, 566-577. http://dx.doi.org/10.1037/0022-3514.77.3.566, PMid:10510509

Alvesson, M., \& Sköldberg, K. (2010). Reflexive methodology. New vistas for qualitative research. London: Sage.

Apfel, R., \& Sifneos, P. (1979). Alexithymia: Concept and measurement. Psychotherapy and Psychosomatics, 32, 180-190. http://dx.doi.org/10.1159/000287386, PMid:550171

Armstrong, D. (2005). Organisation in the mind. Psychoanalysis, group relations and organisational consultancy. London: Karnac.

Avolio, B.J. (2007). Promoting more integrative strategies for leadership theory building. American Psychologist, 62(1), 25-33. http://dx.doi.org/10.1037/0003 066X.62.1.25, PMid:17209677

Babiak, P., \& Hare, R. (2006). Snakes in suits. When psychopaths go to work. New York: Harper Collins.

Bass, B.M. (1997). Does the transactional-transformational leadership paradigm transcend organizational and national boundaries? American Psychologist, 52(2) 130-139. http://dx.doi.org/10.1037/0003-066X.52.2.130

Bass, B.M., \& Avolio, B.J. (1994). Improving organizational effectiveness. Thousand Oaks: Sage.

Berenbaum, H., \& Irvin, S. (1996). Alexithymia, anger, and interpersonal behavior. Psychotherapy and Psychosomatics, 65, 203-208. http://dx.doi. org/10.1159/000289076, PMid:8843501

Berenbaum, H., \& Prince, J.D. (1994). Alexithymia and the interpretation of emotion relevant information. Cognition and Emotion, 3, 231-244. http://dx.doi. org/10.1080/02699939408408939

Bion, W.R. (1961). Experiences in groups. London: Tavistock. http://dx.doi. org/10.4324/9780203359075
Bion, W.R. (2003). Learning from experience. London: Karnac.

Blackman, J.S. (2004). 101 Defences. How the mind shields itself. New York: BrunnerRoutledge.

Blake, R.R., \& McCanse, A.A. (1995). Leadership dilemmas - grid solutions. Houston: Griff.

Boydell, L. (2009). Analysing discourse psycho-socially. In S. Clarke \& P. Hoggett (Eds.), Researching beneath the surface. Psycho-social research methods in practice (pp. 241-266). London: Karnac.

Brewerton, P., \& Millward, L. (2004). Organisational research methods. A guide for students and researchers. London: Sage.

Brunner, L.D., Nutkevitch, A., \& Sher, M. (2006). Group relations conferences. Reviewing and exploring theory, design, role-taking and application. London: Karnac.

Brunning, H. (2006). Executive coaching. Systems-Psychodynamic perspective. London: Karnac.

Bycio, P., Hackett, R.D., \& Allen, J.S. (1995). Further assessment of Bass's (1985) conceptualization of transactional and transformational leadership. Journa of Applied Psychology, 80(4), 468-478. http://dx.doi.org/10.1037/0021 9010.80.4.468

Camic, P.M., Rhodes, J.E., \& Yardley, L. (2003). Qualitative research in Psychology. Washington: APA.

Campbell, D. (2007). The socially constructed organisation. London: Karnac.

Campbell, D., \& Groenbaek, M. (2006). Taking positions in the organisation. London: Karnac.

Campbell, D., \& Huffington, C. (2008). Organisations connected. A handbook of systemic consultation. London: Karnac.

Chamberlayne, P., Bornat, J., \& Apitzsch, U. (2004). Biographical methods and professional practice. An international perspective. Bristol: Policy Press.

Chapman, L., \& Cilliers, F. (2008). The integrated experiential executive coaching model: A qualitative exploration. South African Journal of Labour Relations, 32(1), 63-80.

Cilliers, F., Rothmann, S., \& Struwig, W.H. (2004). Transference and countertransference in systems psycho-dynamic group process consultation: The consultant's experience. South African Journal of Industrial Psychology, 30(1), consult. $72-81$.

Clarke, S., \& Hoggett, P. (2009). Researching beneath the surface. Psycho-social research methods in practice. London: Karnac.

Colin, V.L. (1996). Human attachment. New York: McGraw-Hill.

Colman, A.D., \& Bexton, W.H. (1975). Group relations reader 1. Jupiter: The A.K. Rice Institute.

Colman, A.D., \& Geller, M.H. (1985). Group relations reader 2. Jupiter: The A.K. Rice Institute.

Coutu, D., \& Kaufman, C. (2009). What can coaches do for you? Harvard Business Review, January, 91-97.

Creswell, J.W. (2003). Research design: Qualitative, quantitative and mixed methods. London: Sage.

Cytrynbaum, S., \& Noumair, A. (2004). Group dynamics, organizational irrationality, and social complexity: Group relations reader 3. Jupiter: A.K. Rice Institute.

Czander, W.M. (1993). The psychodynamics of work and organizations. New York: Guilford.

De Vos, A.S., Strydom, H., Fouche, C.B., \& Delport, C.S.L. (2002). Research at grass roots. For the social sciences and human service professions. Pretoria: Van Schaik.

Denzin, N.K., \& Lincoln, Y.S. (2005). The Sage handbook of qualitative research. London: Sage.

Dewaraja, R., Tanigawa, T., Araki, S., Nakata, A., Kawamura, N., Ago, Y., \& Sasaki, Y. (1997). Decreased cytotoxic lymphocyte counts in alexithymia. Psychotherapy and Psychosomatics, 66(2), 83-86. http://dx.doi.org/10.1159/000289113 PMid:9097335

Diamond, M.A., \& Allcorn, S. (2009). Private selves in public organizations. The psychodynamics of organisational diagnosis and change. New York: Palgrave.

Fraher, A. (2004). A history of group study and psychodynamic organizations. London: Free Association.

Friedlander, L., Lumley, M., Farchione, T., \& Doyal, G. (1997). Testing the alexithymia hypothesis: Physiological and subjective responses during relaxation and stress. Journal of Nervous and Mental Disease, 184(4), 233-239. http://dx.doi. org/10.1097/00005053-199704000-00003

Fromm, E. (1947). Man for himself. New York: Holt, Rinehart \& Winston.

Goleman, D., Boyatzis, R., \& Mckee, A. (2008). The new leaders. Transforming the art of leadership into the science of results. London: Sphere.

Gould, L.J., Stapley, L.F., \& Stein, M. (2001). The systems psychodynamics of organisations. London: Karnac.

Gould, L.J., Stapley, L.F., \& Stein, M. (2004). Experiential learning in organizations. Application of the Tavistock Group Relations Approach. London: Karnac.

Harvard Business Essentials. (2004). Coaching and mentoring. How to develop top talent and achieve stronger performance. Boston: Harvard Business School.

Hinshelwood, R.D., \& Skogstad, W. (2005). Observing organisations. Anxiety, defence and culture in health care. London: Routledge.

Hirschhorn, L. (1997). Reworking authority. Leading and following in the post-modern organisation. London: MIT. 
Hollway, W., \& Jefferson, T. (2010). Doing qualitative research differently. Free association, narrative and the interview method. London: Sage.

Huffington, C., Armstrong, A., Halton, W., Hoyle, L., \& Pooley, J. (2004). Working below the surface. The emotional life of contemporary organisations. London: Karnac.

Hughes, M., \& Terrell, J.B. (2007). The emotionally intelligent team. Understanding and developing the behaviours of success. San Francisco: Jossey-Bass.

Hunt, J. (1989). Psychoanalytic aspects of fieldwork. London: Sage.

Izard, C. (1990). Facial expressions and the regulation of emotions. Journal of Personality and Social Psychology, 58, 487-498. http://dx.doi.org/10.1037/0022 Personality and Social Psycholog

Jaques, E. (1990). Creativity and work. Madison: International Universities.

Kauhanen, J., Kaplan, G., Cohen, R., Salonen, R., \& Salonen, J. (1994). Alexithymia may influence the diagnosis of coronary heart disease. Psychosomatic Medicine, 56(3), 237-244

Kegan, R. (1994). In over our heads. The mental demands of modern life. Cambridge: Harvard University.

Kets De Vries, M.F.R. (2001). The leadership mystique. London: Prentice Hall.

Kets De Vries. M.F.R. (2006). The leader on the coach. A clinical approach to changing people and organisations. New York: Jossey-Bass.

Kets De Vries, M.F.R. (2007). Coach and couch. The psychology of making better leaders. London: Palgrave.

Kets De Vries, M.F.R., \& Engellau, E. (2007). Organisational dynamics in action. In R.R Kilburg, (Ed.), Executive wisdom. Coaching and the emergence of virtuous leaders (pp. 21-52) Washington: APA

Kilburg, R., \& Diedrich, R. (2007). The wisdom of coaching: Essential papers in consulting psychology for a world of change. Washington: American Psychological Association. http://dx.doi.org/10.1037/11570-000

King, L. (1998). Ambivalence over emotional expression and reading emotions in situations and faces. Journal of Personality and Social Psychology, 74, 753-762. $\mathrm{http}: / / \mathrm{dx}$.doi.org/10.1037/0022-3514.74.3.753, PMid:9523417

King, L., \& Emmons, R. (1990). Conflict over emotional expression: Psychological and physiological correlates. Journal of Personality and Social Psychology, 58, 864877. http://dx.doi.org/10.1037/0022-3514.58.5.864, PMid:2348373

Klein, L. (2005). Working across the gap. The practice of social science in organisations London: Karnac.

Kooiman, C. (1998). The status of alexithymia as a risk factor in medically unexplained physical symptoms. Comprehensive Psychiatry, 39(3), 152-159. http://dx.doi. org/10.1016/S0010-440X(98)90075-X

Lane, R., Ahern, G., Schwartz, G., \& Kaszniak, A. (1997). Is alexithymia the emotional equivalent of blindsight? Biological Psychiatry, 42(9), 834-844. http://dx.doi. org/10.1016/S0006-3223(97)00050-4

Lane, R., \& Schwartz, G. (1987). Levels of emotional awareness: A cognitivedevelopmental theory and its application to psychopathology. The American Journal of Psychiatry, 144(2), 133-143.

Lane, R., Sechrest, L., Reidel, R., Weldon, V., Kaszniak, A., \& Schwartz, G. (1996) Impaired verbal and nonverbal emotion recognition in alexithymia. Psychosomatic Medicine, 58(3), 203-210.

Lawrence, W.G., Bain, A., \& Gould, L. (1996). The fifth basic assumption. London: Tavistock.

Lowman, R.L. (2002). The handbook of organizational consulting Psychology. San Francisco: Jossey-Bass.

Lumley, M., Gustavson, B., Partridge, R., \& Labouvie-Vief, G. (2005). Assessing alexithymia and related emotional ability constructs using multiple methods: Interrelationships among measures. Emotion, 5(3), 329-342. http://dx.doi. org/10.1037/1528-3542.5.3.329, PMid:16187868

McCluskey, U. (2005). To be met as a person. The dynamics of attachment in professional encounters. London: Karnac.

McGovern, J., Lindemann, M., Vergara, M., Murphy, S., Barker, L., \& Warrenfeltz, R. (2001). Maximizing the impact of executive coaching. Behavioural change, organisational outcomes and return on investment. The Manchester Review, 6(1) $1-10$.
McKenna, D.D., \& Davis, S.L. (2009). Hidden in plain sight: The active ingredient of executive coaching Industrial and Organisational Psychology, 2(3), 244-260. $\mathrm{http}: / / \mathrm{dx}$.doi.org/10.1111/j.1754-9434.2009.01143.x

Meyer, T.N.A., \& Boninelli, I. (2007). Conversations in leadership. South African perspectives. Randburg: Knowres.

Miller, E.J. (1993). From dependency to autonomy: Studies in organization and change. London: Free Association.

Morgan-Jones, R. (2010). The body of the organisation and its health. London: Karnac.

Nelson, E., \& Hogan, R. (2009). Coaching on the dark side. International Coaching Psychology Review, 4(1), 7-16.

Neumann, J.E., Kellner, K., \& Dawson-Shepherd, A. (1997). Developing organisational consultancy. London: Routledge.

Newton, J., Long, S., \& Sievers, B. (2006). Coaching in depth. The organisational role analysis approach. London: Karnac.

Nohria, N., \& Khurana, R. (2010). Handbook of leadership theory and practice. Boston Harvard Business Press.

Northouse, P.G. (2004). Leadership. Theory and practice. Thousand Oaks: Sage.

Obholzer, A., \& Roberts, V.Z. (1994). The unconscious at work. London: Routledge. http://dx.doi.org/10.4324/9780203359860

Prior, V., \& Glaser, D. (2006). Understanding attachment and attachment disorders. Theory, evidence and practice. London: Jessica Kingsley.

Rholes, W.S., \& Simpson, J.A. (2004). Adult attachment. Theory, research and clinical implications. New York: Guilford.

Schafer, R. (2003). Insight and interpretation. The essential tools of psychoanalysis. London: Karnac.

Seligman, M.E.P. (2003). Authentic happiness. London: Nicholas Brealey.

Sievers, B. (2009). Psychoanalytic studies of organizations. Contributions from the International Society for the Psychoanalytical Study of Organizations (ISPSO). London: Karnac.

Snyder C.R., \& Lopez, A.J. (2002). Handbook of positive psychology. New York: Oxford.

Sperry, L. (2004). Executive coaching. The essential guide for mental health professionals. New York: Brunner-Routledge.

Stake, R. (1995). The art of case study research. Thousand Oaks. Sage.

Stapley, L.F. (1996). The personality of the organisation. A psycho-dynamic explanation of culture and change. London: Free Association.

Stapley, L.F. (2006). Individuals, groups and organisations beneath the surface. London: Karnac.

Stout Rostron, S. (2009). Business coaching. Wisdom and practice. Unlocking the secrets of business coaching. Randburg: Knowledge Resources.

Taylor, G., Bagby, M., \& Parker, J. (1997). Disorders of affect regulation: Alexithymia in medical and psychiatric illness. New York, NY: Cambridge University Press. http:// dx.doi.org/10.1017/CBO9780511526831

Terre Blanche, M., Durrheim, K., \& Painter, D. (2006). Research in practice. Applied methods for the social sciences. Cape Town: UCT Press.

Turquet, P.M. (1974). Leadership - the individual in the group. In: G.S. Gibbard, J.J. Hartman \& R.D. Mann (Eds.), Analysis of groups (pp. 52-67). San Francisco: Jossey-Bass.

Van Eeden, R., Cilliers, F., \& Van Deventer, V. (2008). Leadership styles and associated personality traits: Support for the conceptualisation of transactional and transformational leadership. South African Journal of Psychology, 38(2), 253-267.

Vansina, L.S., \& Vansina-Cobbaert, M. (2008). Psychodynamics for consultants and managers. From understanding to leading meaningful change. Chichester: WileyBlackwell.

Wall, B. (2007). Coaching for emotional intelligence. New York: Amacom.

Watts, L. (2009). Managing self in role: Using multiple methodologies to explore self construction and self governance. In S. Clarke \& P. Hoggett (Eds.), Researching beneath the surface. Psycho-social research methods in practice (pp. 215-239). London: Karnac. 